\title{
Material Characterization and Parametric Optimization of Unconventional Machining of TiN and TaC reinforced Stir Casted Vitallium Metal Matrix Composite
}

\author{
M. Prabhu $^{a, *}$ (D), P. Shanmughasundaram ${ }^{b}$ \\ ${ }^{a}$ Saveetha School of Engineering, Department of Mechanical Engineering, Chennai, Tamilnadu, India. \\ ${ }^{b}$ Karpagam Academy of Higher Education, Department of Automobile Engineering, Coimbatore, 641021, India.
}

Received: May 03, 2019; Revised: May 26, 2020; Accepted: May 27, 2020

\begin{abstract}
In this work, influence of machining parameters of the electro discharge machining (EDM) and Abrasive-water jet machining (AWJM) processes on the material removal rate, tool wear rate and surface roughness of the composites were investigated. Titanium nitride and tantalum carbide particles reinforced vitallium composite material was synthesized by stir casting method. The machining characteristics were analyzed through Taguchi and ANOVA methods. The Taguchi optimization technique was used to find the optimal level of parameters while the percentage of contribution for each input parameter on the responses was computed by ANOVA. Scanning electron microscope (SEM) was employed to examine the surface morphology.
\end{abstract}

Keywords: vitallium composite material, Electric discharge machining, Abrasive water jet machining process, material removal rate, tool wear rate, surface roughness.

\section{Introduction}

The vitallium metal matrix is mainly used in medical applications like making of artificial joints, dental and surgical appliances. It is also used in the fabrication of turbochargers components, aircraft jet engines, turbine, machine tools, electrical, electronic equipments and medical industries ${ }^{1}$. Microstructure and mechanical properties of cobalt-based alloys strengthened with tantalum carbide powder was investigated. It is reported that $\mathrm{TiC}$ particles play an important role in enhancing the mechanical properties of cobalt-based alloy ${ }^{2}$. Stir casting is a simple, flexible and more economical process used. It is for producing large size of casting components ${ }^{3}$.

Maneiah et al. ${ }^{4}$ optimized the machining parameters in order to attain the surface finish during abrasive water jet machining of $\mathrm{Al} / \mathrm{Mg}$ hybrid metal matrix composites. Tests were performed by selecting the operational parameters such as a stand of distance, feed rate, and abrasive flow rate. The influence of water jet machining parameters on the surface roughness of the Al 6063 reinforced with boron carbide and zirconium silicate. The results revealed that higher abrasive flow rate, lower traverse rate, and higher water jet pressure in obtaining the higher material removal rate and lower surface roughness ${ }^{5}$ Yue et al. ${ }^{6}$ optimized the machining parameters in the abrasive water jet turning of alumina ceramic based on the response surface methodology. Kechagias et al. ${ }^{7}$ applied Taguchi method for exploring the abrasive water jet machining characteristics in machining of TRIP sheet steels. Response variables such as mean kerf width and average surface roughness were selected. Pawar et al. ${ }^{8}$ studied the quality characteristics of abrasive water jet machining of marble material using multi-objective artificial bee colony

*e-mail: nitprabhume@gmail.com algorithm. The response surface modeling was used to establish the relation between input factors such as stand of distance, traverse speed, water pressure, and abrasive flow rate, with kerf width and kerf taper. Ćojbašić et al. ${ }^{9}$ reported that the surface roughness is the most important variable to evaluate influence of machining parameters on the surface quality. Kumaran et al. ${ }^{10}$ predicted the surface roughness of CFRP composites using regression analysis in abrasive water jet machining. They conducted the tests based on an L27 orthogonal array by varying the process parameters such as jet pressure, traverse speed, and standoff distance. Nain et al. ${ }^{11}$ optimized the level of process parameters of wirecut electric discharge machining of super alloy Udimet-L605 in obtaining the better surface roughness. They concluded that pulse-on time, pulse-off time, spark-gap voltage and wire tension were important factors which decide the surface roughness and material removal rate. Kar et al. ${ }^{12}$ studied the Influence of factors in Electric Discharge Machining of Aluminum - red mud MMCs. They studied the relationship between the process variables and material removal rate, electrode wear rate and radial over cut. They reported that the current is significant factor compared with pulse on time and gap voltage. Kanagarajan et al. ${ }^{13}$ studied the influence of electrical discharge machining on strength and reliability of composite. The comparison of results between the machined composites and un-machined composites was carried out. Chakravorty et al. ${ }^{14}$ optimized operational parameters of EDM process. Mohanty et al. ${ }^{15}$ analyzed the EDM Characteristics of Inconel 825. They studied the effect of EDM process factors such as peak current, duty factor, and pulse-on duration on material removal rate, surface roughness, radial overcut, and surface crack density. Experiments were performed based on L9 orthogonal array. Singh et al. ${ }^{16}$ studied the 
Influence of process parameters on MRR during the EDM of AA $6061 / 10 \% \mathrm{SiC}$ composite. The effect of peak current, pulse on time, pulse off time and gap voltage are studied. They reported that process parameters play considerable role on MRR. Sivaraj and Selvakumar ${ }^{17}$ analyzed the EDM process parameters Using ANOVA. They optimized the parameters such as current, pulse-on time and gap voltage on metal removal rate and tool wear rate during EDM of Al-5\%MMC. Electric discharge machining is a thermal energy based process used to machine hard materials with more dimensional accuracy. The eroded material surfaces mainly depends on the amount of input current supplied in the EDM process ${ }^{18-20}$.

The empirical model was developed to predict the response during electro discharge machining of ceramics ${ }^{21}$. It was reported that the grit size was the most significant influence factor on surface roughness during abrasive water jet machining of graphite ${ }^{22}$. High hardness material such as tungsten carbide, stellite, nimonic, inconel and metal matrix composites can be successfully machined by EDM with a tolerances range of $+/-0.005$. Since there is no tool contact and no force involved, it can be suited for delicate parts. Abrasive-water jet machining (AWJM) is widely employed in the cutting of hard and low machinability materials like. The process makes use of the impact of a water jet and abrasives for improving the machinability of the materials such as titanium alloys, ceramics and metal-matrix composites. More over it is suitable for cutting complex contours on wide range of materials.

At present the usage of metal matrix composites is steadily increasing because of its excellent mechanical properties. In order to meet the demand of applications, vitallium metal matrix composite was produced by the stir casting process. The vitallium metal matrix is reinforced with titanium nitride and tantalum carbide particles.

In this study, the effect of machining parameters of the electro discharge machining (EDM) and Abrasive-water jet machining (AWJM) processes on the material removal rate, tool wear rate and surface roughness of the machined surfaces of the vitallium composite material. Taguchi and ANOVA methods were used to find the optimal level of parameters and the contribution of the each factor on the responses. Surface morphology was studied by the Scanning electron microscope (SEM).

\section{Materials and Methodology}

\subsection{Stir casting process}

The vitallium metal matrix composite was prepared through stir casting furnace which is shown in Figure 1. The raw material of cobalt, chromium and molybdenum was kept inside the crucible and the furnace was operated at $1000^{\circ} \mathrm{C} .5 \mathrm{vol} \%$ of titanium nitride and $5 \mathrm{vol} \%$ of tantalum carbide particles were used as reinforcements. The mechanical stirring was used to mix the reinforcement particles in the molten metal. To achieve the complete melted stage, the mixture was heated above its liquidus temperature and then slowly cooled down. The preheated particles of titanium nitride and tantalum carbides were added to the molten metal in semi solid stage. Again the furnace temperature was raised and achieved liquid stage. The stirrer was applied at $600 \mathrm{rpm}$ for $20 \mathrm{~min}$. This molten metal was poured into the die and the required shape and size of specimens (Figure 1) were obtained.

\subsection{Material characterization}

The specimens were prepared according to ASTM standard ${ }^{23,24}$ and the tests were carried out by using universal testing machine (UTM). The mechanical properties were measured as hardness (122BHN), tensile strength (516 MPa) and Impact strength $(11 \mathrm{~J})$. Thermal conductivity of Vitallium is $14 \mathrm{~W} / \mathrm{mK}$, Thermal expansion coefficient is $12 \mu \mathrm{m} / \mathrm{mK}$, melting temperature is $1400^{\circ} \mathrm{C}$ and specific heat capacity is $450 \mathrm{~J} / \mathrm{Kg}^{\circ} \mathrm{C}$.

\subsection{Electric discharge machining (EDM) process}

The vitallium metal matrix composite was machined by electronica model electro discharge machine. During the machining process, three different levels of input parameters such as current (5A.10A and 15A), pulse on time $(100,200,300 \mu \mathrm{s})$ and voltage $(30 \mathrm{~V}, 40 \mathrm{~V}$ and $50 \mathrm{~V})$ were considered. The material removal rate (MRR), tool wear rate (TWR) and surface roughness (SR) were considered as the output parameters. The graphite was the electrode material and kerosene was the dielectric fluid. The diameter $5 \mathrm{~mm}$ holes were produced on the surface. The surface roughness was measured by the surface profile meter (Figure 2). The machined surface was analyzed through a scanning electron microscope.

\subsection{Abrasive water jet machining (AWJM) process}

The vitallium metal matrix composite materials was machined by KEBER model AWJM machine. Three different levels of input parameters such as water pressure (1200,1700,2200 bar), traverse speed $(40,60,100 \mathrm{~mm} / \mathrm{min})$ and abrasive flow rate $(100,200,300 \mathrm{gm} / \mathrm{min})$ were considered. The material removal rate (MRR), tool wear rate (TWR) and surface roughness

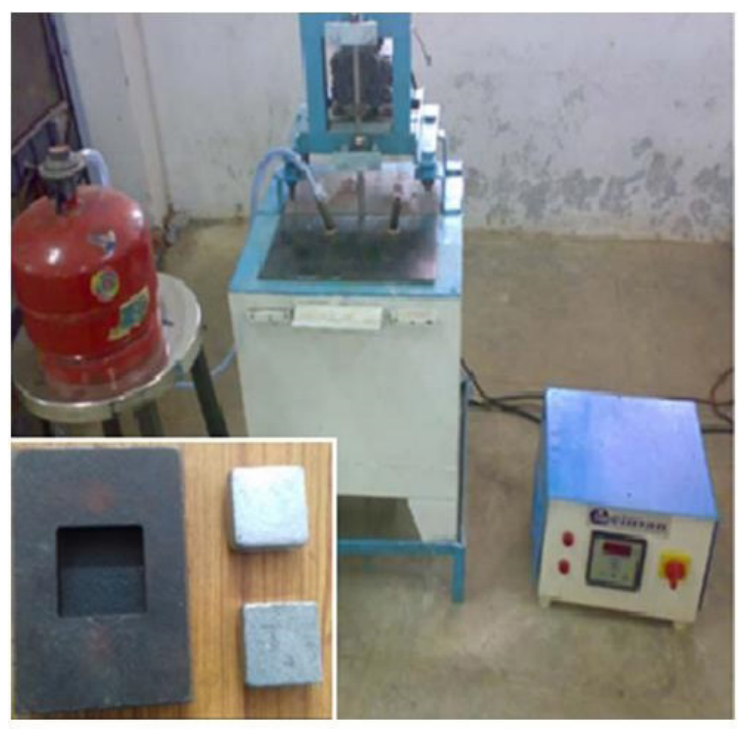

Figure 1. Stir casting furnace. 
(SR) were considered as the output parameters. The silicon nitride and boron carbide materials were mixed with the slurry. $5 \mathrm{~mm}$ diameter holes were produced on the surface.

Optimal levels of parameters for both the EDM and AWJM processes are identified using Taguchi method. It reduces test runs, duration and the cost. A Taguchi based, three levels L9 orthogonal array was selected. Nine tests were conducted. Since the lower tool wear rate and surface roughness are enviable, "Smaller is better" $\mathrm{S} / \mathrm{N}$ ratio was selected. Since the higher material removal rate is enviable, "Larger is better" $\mathrm{S} / \mathrm{N}$ ratio was selected.

\section{Results and Discussions}

\subsection{Taguchi method}

Taguchi method was used to find the optimal level of parameters in obtaining the desired output. L9 orthogonal array was selected for this study. EDM experimental results are shown in Table 1.

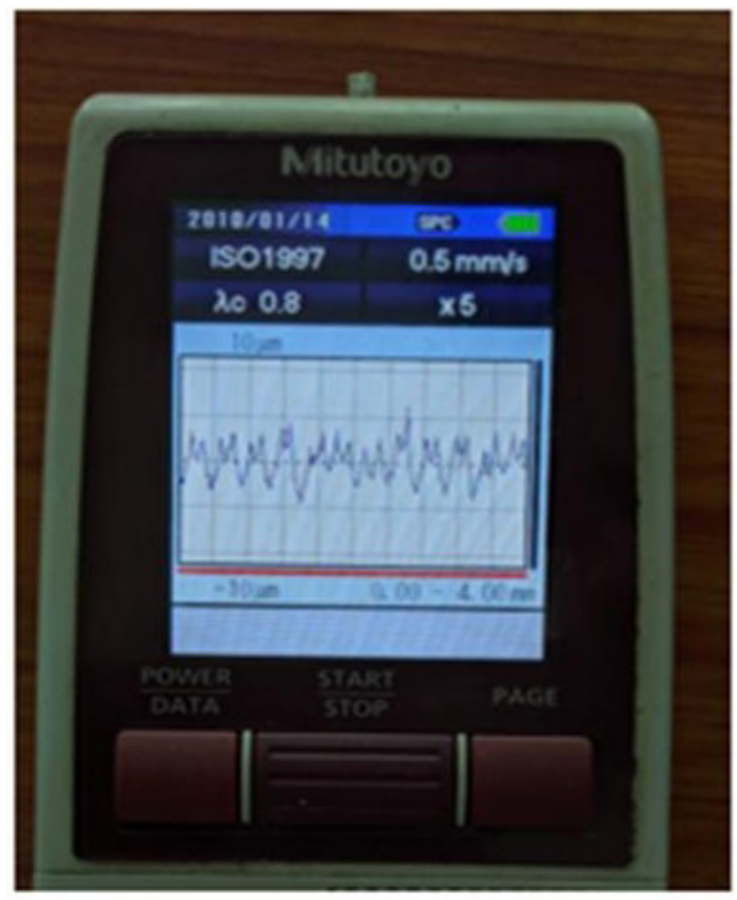

Figure 2. Surface roughness tester Composite specimen.

\subsection{EDM parametric optimization}

The Table 2 shows that ranking of the parameters for the MRR, TWR and SR. Table 2 infers that current was found to be dominant factor followed by voltage and pulse on time on the MRR. Current was found to be dominant factor followed by pulse on time and voltage on the TWR while pulse on time was found to be dominant factor followed by current and voltage on the surface roughness of the composites.

The main effect plots were drawn for MRR, TWR and SR which are shown in Figures 3-5. The main aim of the experiment was to maximize the material removal rate. Hence, larger the better criterion was considered for MRR. In Figure 3, the maximum material removal rate was achieved when the level of current was 15 amps, pulse on time was $300 \mu \mathrm{s}$ and voltage was $50 \mathrm{~V}$. Smaller the better criterion was considered for TWR in order to minimize the tool wear. In Figure 4, the minimum TWR was achieved when the level of current was 5 amps, pulse on time was $100 \mu \mathrm{s}$ and voltage was $50 \mathrm{~V}$.

Smaller the better criterion was considered for SR in order to minimize the surface roughness. In Figure 5, the minimum surface roughness was achieved when the level of current, pulse on time and voltage were 5 amps, $100 \mu \mathrm{s}$ and $30 \mathrm{~V}$ respectively.

The ANOVA technique was applied to find the percentage of contribution for each input parameter on the responses such as MRR, TWR and SR. Table 3 shows that the analysis of variance for MRR.

It can be observed from the Table 3 that current was found to be significant factor compared to other factors on the MRR as it has $\mathrm{p}$ value below 0.05 .

It can be inferred from the Figure 6 that current $(73.89 \%)$ was the most influential parameter on material removal rate. The voltage (15.72\%) was the second influential parameter followed by pulse on time which contributes $8.23 \%$. Table 3 infers that that current was found to be significant factor on the TWR as it has p value below or equal to 0.05 . Figure 6 infers that current (50.72\%) was the most influential parameter on tool wear rate. The pulse on time $(40.87 \%)$ was the second influential parameter followed by voltage which contributes $5.43 \%$.

It can be observed from the Table 3 that current and pulse on time was found to be significant factors on the SR as they have $\mathrm{p}$ value below 0.05 . Figure 6 shows that current $(45.35 \%)$ was the most influential parameter followed by pulse on time $(44.91 \%)$ on surface roughness. The voltage

Table 1. EDM experimental results.

\begin{tabular}{|c|c|c|c|c|c|c|}
\hline S.No. & Current (A) & $\begin{array}{c}\text { Pulse ON Time } \\
(\mu \mathrm{s})\end{array}$ & Voltage (V) & $\operatorname{MRR}\left(\mathrm{mm}^{3} / \mathrm{min}\right)$ & TWR $\left(\mathrm{mm}^{3} / \mathrm{min}\right)$ & $\begin{array}{c}\text { Surface } \\
\text { roughness }(\mu \mathrm{m})\end{array}$ \\
\hline 1 & 5 & 100 & 30 & 4.67 & 0.34 & 4.36 \\
\hline 2 & 5 & 200 & 40 & 5.33 & 0.42 & 5.35 \\
\hline 3 & 5 & 300 & 50 & 8.62 & 0.59 & 6.07 \\
\hline 4 & 10 & 100 & 40 & 7.94 & 0.55 & 4.95 \\
\hline 5 & 10 & 200 & 50 & 11.39 & 0.81 & 5.9 \\
\hline 6 & 10 & 300 & 30 & 8.77 & 1.03 & 5.77 \\
\hline 7 & 15 & 100 & 50 & 11.98 & 0.56 & 5.98 \\
\hline 8 & 15 & 200 & 30 & 10.91 & 1.11 & 6.19 \\
\hline 9 & 15 & 300 & 40 & 12.96 & 1.24 & 7.36 \\
\hline
\end{tabular}


Table 2. Mean of SN ratios for the MRR, TWR and SR -EDM.

\begin{tabular}{|c|c|c|c|c|}
\hline & Level & Current (A) & Pulse ON Time $(\mu \mathrm{s})$ & Voltage (V) \\
\hline \multirow{5}{*}{ MRR } & 1 & 15.54 & 17.65 & 17.67 \\
\hline & 2 & 19.33 & 18.81 & 18.26 \\
\hline & 3 & 21.53 & 19.94 & 20.47 \\
\hline & Delta & 5.98 & 2.29 & 2.80 \\
\hline & Rank & 1 & 3 & 2 \\
\hline \multirow{5}{*}{ TWR } & 1 & 7.1628 & 6.5331 & 2.7357 \\
\hline & 2 & 2.2554 & 2.8196 & 3.6198 \\
\hline & 3 & 0.7538 & 0.8193 & 3.8165 \\
\hline & Delta & 6.4090 & 5.7139 & 1.0808 \\
\hline & Rank & 1 & 2 & 3 \\
\hline \multirow{5}{*}{ SR } & 1 & -14.34. & -14.07 & -14.62 \\
\hline & 2 & -14.84 & -15.27 & -15.27 \\
\hline & 3 & -16.24 & -16.07 & -15.54 \\
\hline & Delta & 1.89 & 2.0 & 0.92 \\
\hline & Rank & 2 & 1 & 3 \\
\hline
\end{tabular}

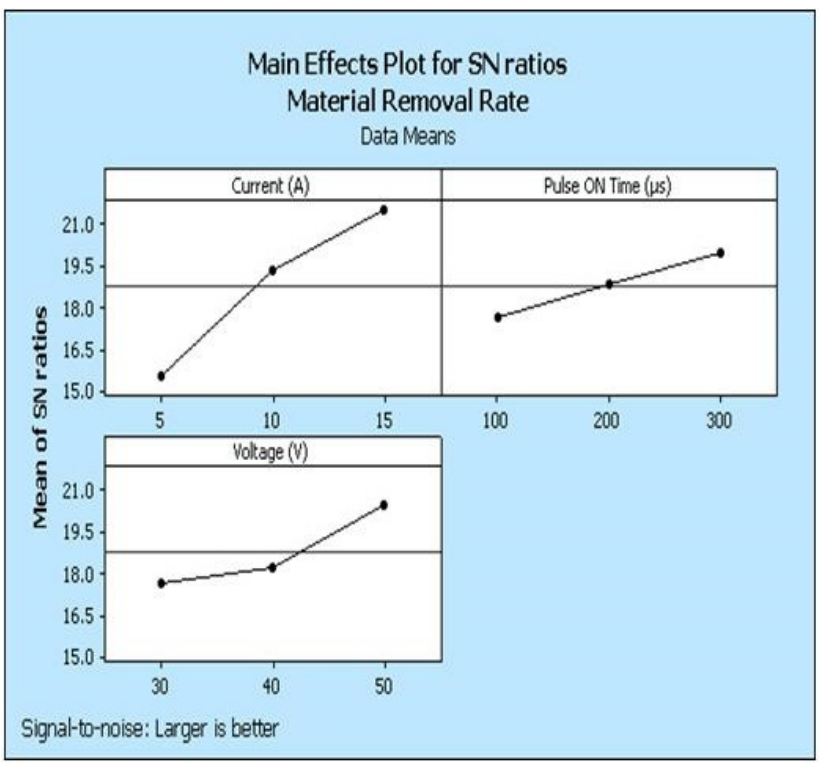

Figure 3. Main effects plot for SN ratios - MRR-EDM.

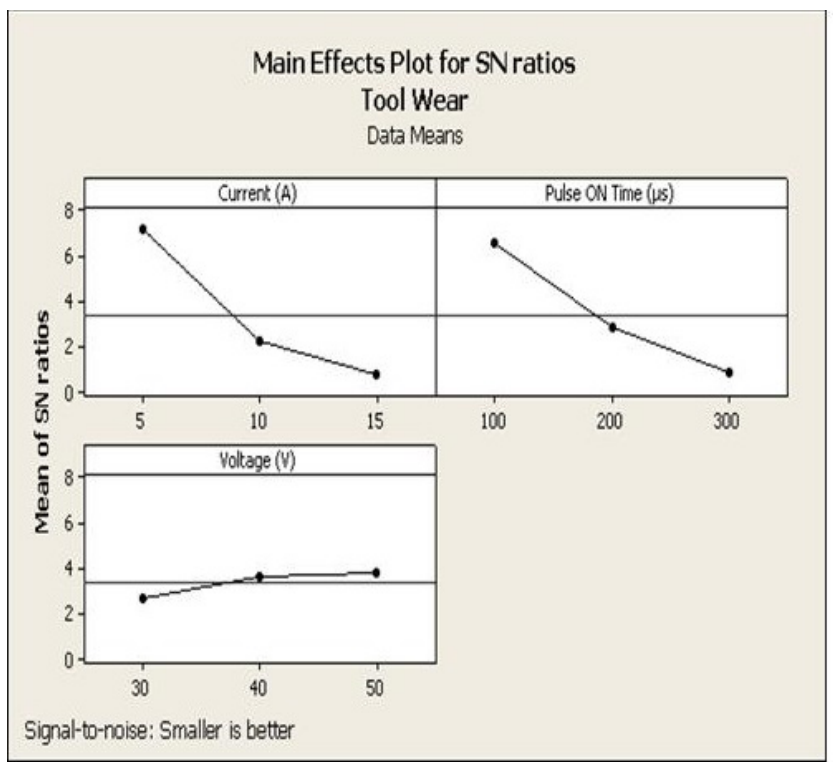

Figure 4. Main effects plot for SN ratios - TWR-EDM. 


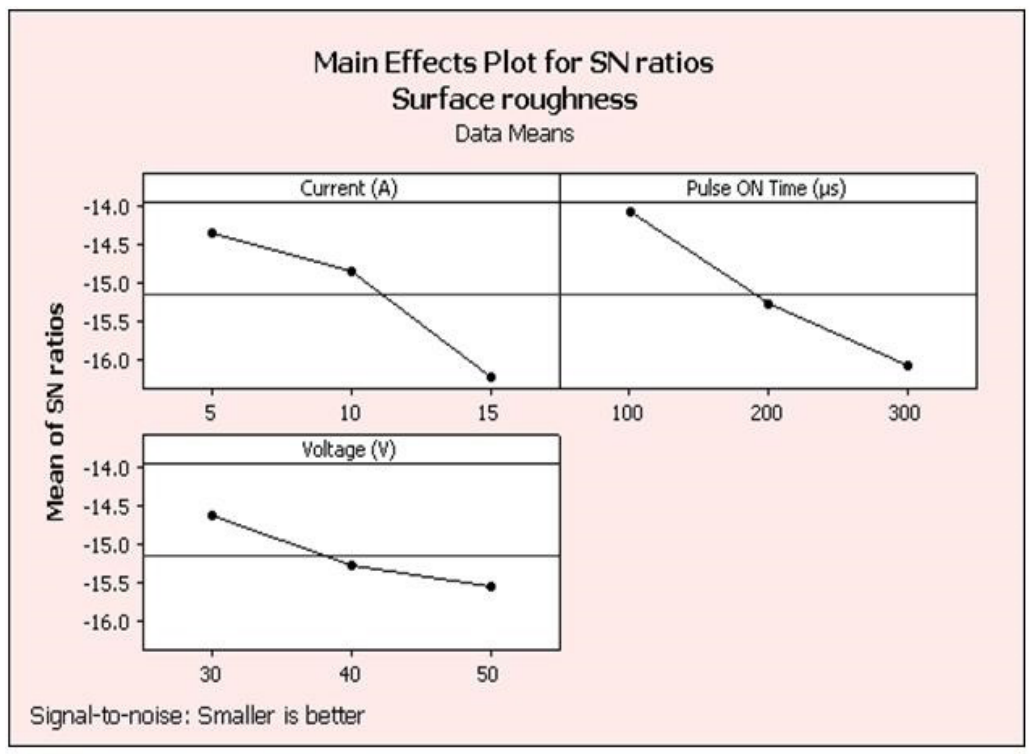

Figure 5. Main effects plot for SN ratios - SR-EDM.

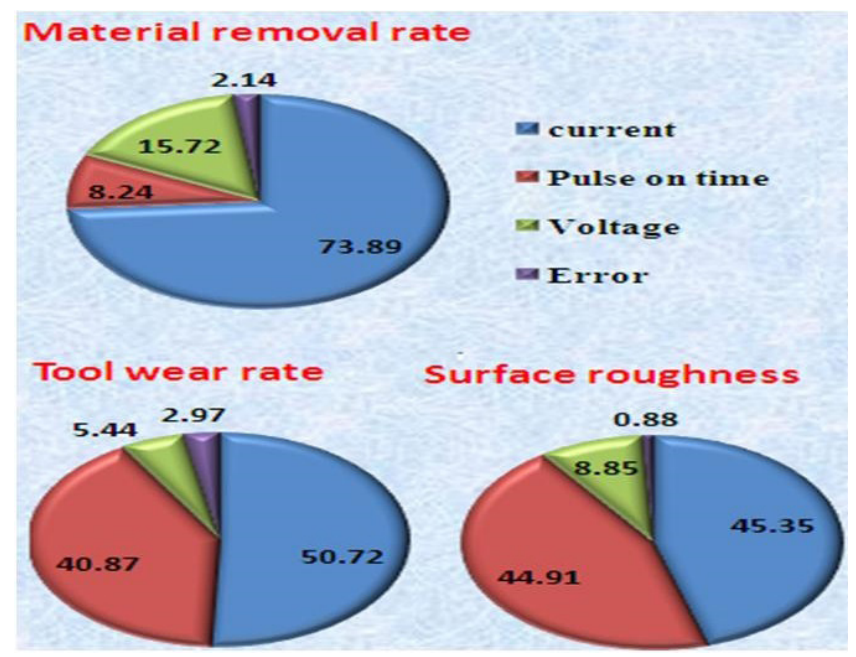

Figure 6. Percentage of contribution for each input parameter on the responses (EDM).

Table 3. Analysis of variance for EDM.

\begin{tabular}{|c|c|c|c|c|c|c|}
\hline Source & DF & Seq. SS & Adj. MS & F-Value & P-Value & Percentage $\%$ \\
\hline \multicolumn{7}{|c|}{ MRR } \\
\hline Current & 2 & 49.645 & 24.823 & 34.43 & 0.028 & 73.89 \\
\hline Pulse ON Time & 2 & 5.535 & 2.768 & 3.84 & 0.207 & 8.24 \\
\hline Voltage & 2 & 10.565 & 5.282 & 7.33 & 0.120 & 15.72 \\
\hline Error & 2 & 1.442 & 0.721 & & & 2.14 \\
\hline Total & 8 & 67.187 & & & & 100 \\
\hline \multicolumn{7}{|c|}{ TWR } \\
\hline Current & 2 & 0.42062 & 0.21031 & 17.08 & 0.055 & 50.72 \\
\hline Pulse ON Time & 2 & 0.33896 & 0.16948 & 13.77 & 0.068 & 40.87 \\
\hline Voltage & 2 & 0.04509 & 0.02254 & 1.83 & 0.353 & 5.44 \\
\hline Error & 2 & 0.02462 & 0.01231 & & & 2.97 \\
\hline Total & 8 & 0.82929 & & & & 100 \\
\hline \multicolumn{7}{|c|}{$\mathrm{SR}$} \\
\hline Current & 2 & 2.58180 & 1.29090 & 51.57 & 0.019 & 45.35 \\
\hline Pulse ON Time & 2 & 2.55647 & 1.27823 & 51.06 & 0.019 & 44.91 \\
\hline Voltage & 2 & 0.50407 & 0.25203 & 10.07 & 0.090 & 8.85 \\
\hline Error & 2 & 0.05007 & 0.02503 & & & 0.88 \\
\hline Total & 8 & 5.69240 & & & & 100 \\
\hline
\end{tabular}


$(8.855 \%)$ was the third influential parameter on surface roughness.

The mathematical model was derived for MRR and given in equation 1 . The regression equation is $=-3.58+$ 0.574 Current $(\mathrm{A})+0.00960$ Pulse ON Time $(\mu \mathrm{s})+0.127$ Voltage (V) --- Eqn. (1)

The mathematical model was derived for TWR and given in equation 2 . The regression equation is $=0.096+0.0520$ Current $(\mathrm{A})+0.00235$ Pulse ON Time $(\mu \mathrm{s})-0.00867$ Voltage $(\mathrm{V})$ --- Eqn. (2)

The mathematical model was derived for SR and given in equation 3 .

The regression equation is $\mathrm{SR}=2.13+0.125$ Current $(\mathrm{A})+0.00652$ Pulse ON Time $(\mu \mathrm{s})+0.0272$ Voltage $(\mathrm{V})$ --- Eqn. (3)

Where A, B and C are current, pulse on time and voltage respectively.

\subsection{Abrasive water jet machining process}

The AWJM experimental results are presented in Table 4.

\subsection{AWJM parametric optimization by Taguchi analysis}

The Abrasive water jet machining process parameters were optimized by Taguchi method. Table 5 infers that water pressure was found to be dominant factor followed by abrasive flow rate and traverse speed on the MRR. On the other hand water pressure was found to be dominant factor followed by traverse speed and abrasive flow rate on the TWR and SR of the composite.

The main effect plots were drawn for MRR, TWR and SR which are shown in Figures 7-9. The main aim of the experiment was to maximize the material removal rate. Hence, larger the better criterion was considered for MRR. In Figure 7, the maximum material removal rate was achieved when the level of water pressure was 2200 bar, pulse traverse speed was $100 \mathrm{~mm} / \mathrm{min}$ and the abrasive flow rate was $300 \mathrm{gm} / \mathrm{mm}$.

The main intend of the experiment was to minimize the tool wear rate. Hence, smaller the better criterion was considered for TWR. In Figure 8, the minimum tool wear rate was achieved when the level of the abrasive flow rate was $100 \mathrm{gm} / \mathrm{min}$, water pressure was $1200 \mathrm{bar}$ and pulse traverse speed was $40 \mathrm{~mm} / \mathrm{min}$. The main purpose of the experiment was to minimize the surface roughness. Hence, smaller the better criterion was considered for SR. In Figure 9, the minimum surface roughness was achieved when the level of abrasive flow rate was $100 \mathrm{gm} / \mathrm{mm}$, water pressure was 1200 bar and traverse speed was $40 \mathrm{~mm} / \mathrm{min}$.

Table 6 shows the analysis of variance for MRR. It can be observed from the table that water pressure, traverse speed and abrasive flow rate were found to be significant factors

Table 4. Abrasive water jet machining experimental results.

\begin{tabular}{ccccccc}
\hline S. No. & $\begin{array}{c}\text { Water Pressure } \\
(\mathrm{bar})\end{array}$ & $\begin{array}{c}\text { Traverse Speed } \\
(\mathrm{mm} / \mathrm{min})\end{array}$ & $\begin{array}{c}\text { Abrasive Flow } \\
\text { rate }(\mathrm{gm} / \mathrm{min})\end{array}$ & MRR $\left(\mathrm{mm}^{3} / \mathrm{min}\right)$ & TWR $\left(\mathrm{mm}^{3} / \mathrm{min}\right)$ & $\begin{array}{c}\text { Surface } \\
\text { roughness }(\mu \mathrm{m})\end{array}$ \\
\hline 1 & 1200 & 40 & 100 & 10.25 & 4.060 & 2.08 \\
\hline 2 & 1200 & 60 & 200 & 14.01 & 6.200 & 3.39 \\
\hline 3 & 1200 & 100 & 300 & 19.74 & 8.120 & 4.53 \\
\hline 4 & 1700 & 40 & 200 & 16.58 & 6.110 & 4.08 \\
\hline 5 & 1700 & 60 & 300 & 20.83 & 9.100 & 5.82 \\
\hline 6 & 1700 & 100 & 100 & 18.21 & 8.059 & 5.30 \\
\hline 7 & 2200 & 40 & 300 & 23.63 & 11.805 & 7.75 \\
\hline 8 & 2200 & 60 & 100 & 21.09 & 10.540 & 7.10 \\
\hline 9 & 2200 & 100 & 200 & 25.27 & 12.420 & 8.35 \\
\hline
\end{tabular}

Table 5. Mean of SN ratios for the MRR, TWR and SR -AWJM.

\begin{tabular}{|c|c|c|c|c|}
\hline & Level & Water pressure & Traverse speed & Abrasive flow rate \\
\hline \multirow{5}{*}{ MRR } & 1 & 23.02 & 24.03 & 23.97 \\
\hline & 2 & 25.32 & 25.26 & 25.12 \\
\hline & 3 & 27.33 & 26.39 & 26.58 \\
\hline & Delta & 4.32 & 2.36 & 2.62 \\
\hline & Rank & 1 & 3 & 2 \\
\hline \multirow{5}{*}{ TWR } & 1 & -15.40 & -16.44 & -16.92 \\
\hline & 2 & -17.68 & -18.50 & -17.82 \\
\hline & 3 & -21.26 & -19.40 & -19.60 \\
\hline & Delta & 5.86 & 2.96 & 2.69 \\
\hline & Rank & 1 & 2 & 3 \\
\hline \multirow{5}{*}{ SR } & 1 & -10.03 & -12.12 & -12.62 \\
\hline & 2 & -14.00 & -14.31 & -13.75 \\
\hline & 3 & -17.75 & -15.35 & -15.40 \\
\hline & Delta & 7.72 & 3.23 & 2.78 \\
\hline & Rank & 1 & 2 & 3 \\
\hline
\end{tabular}


Table 6. Analysis of variance - AWJM

\begin{tabular}{|c|c|c|c|c|c|c|}
\hline Source & DF & Seq. SS & Adj. MS & F-Value & P-Value & Percentage $\%$ \\
\hline \multicolumn{7}{|c|}{ MRR } \\
\hline Water pressure & 2 & 113.000 & 56.500 & 267.13 & 0.004 & 63.93 \\
\hline Traverse speed & 2 & 27.320 & 13.660 & 64.58 & 0.015 & 15.45 \\
\hline Abrasive flow rate & 2 & 35.999 & 18.000 & 85.10 & 0.012 & 20.37 \\
\hline Error & 2 & 0.423 & 0.212 & & & 0.24 \\
\hline Total & 8 & 176.743 & & & & 100 \\
\hline \multicolumn{7}{|c|}{ TWR } \\
\hline Water pressure & 2 & 47.170 & 23.585 & 165.52 & 0.006 & 76.25 \\
\hline Traverse speed & 2 & 7.381 & 3.690 & 25.90 & 0.037 & 11.93 \\
\hline Abrasive flow rate & 2 & 7.029 & 3.515 & 24.67 & 0.039 & 11.36 \\
\hline Error & 2 & 0.285 & 0.142 & & & 0.46 \\
\hline Total & 8 & 61.865 & & & & 100 \\
\hline \multicolumn{7}{|c|}{ SR } \\
\hline Water pressure & 2 & 29.4756 & 14.7378 & 308.25 & 0.003 & 84.56 \\
\hline Traverse speed & 2 & 3.0544 & 1.5272 & 31.94 & 0.030 & 8.76 \\
\hline Abrasive flow rate & 2 & 2.2332 & 1.1166 & 23.35 & 0.041 & 6.40 \\
\hline Error & 2 & 0.0956 & 0.0478 & & & 0.27 \\
\hline Total & 8 & 34.8588 & & & & 100 \\
\hline
\end{tabular}

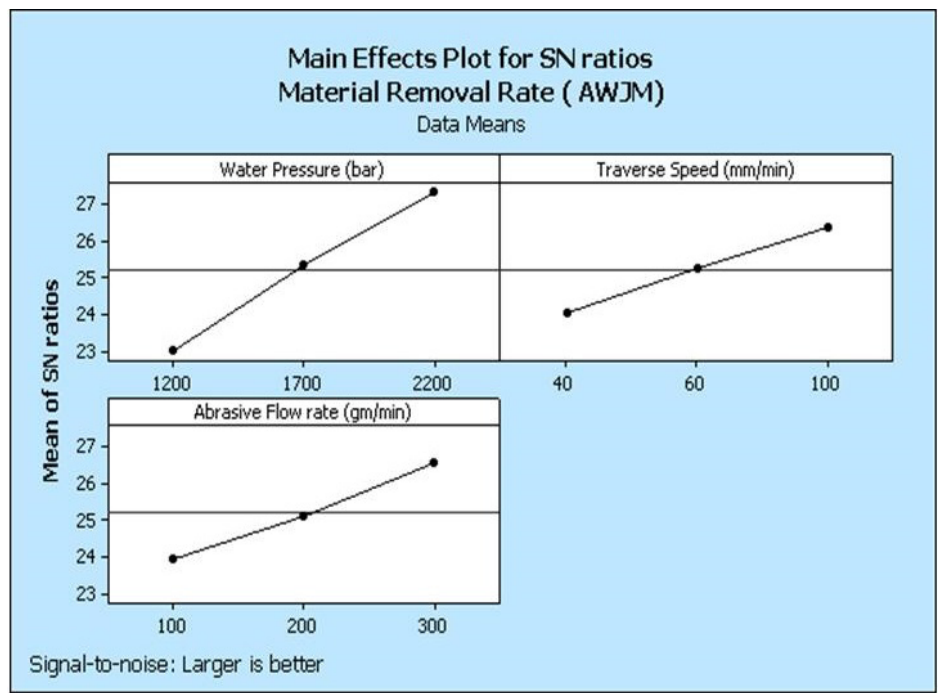

Figure 7. Main effects plot for SN ratios - MRR-AWJM.

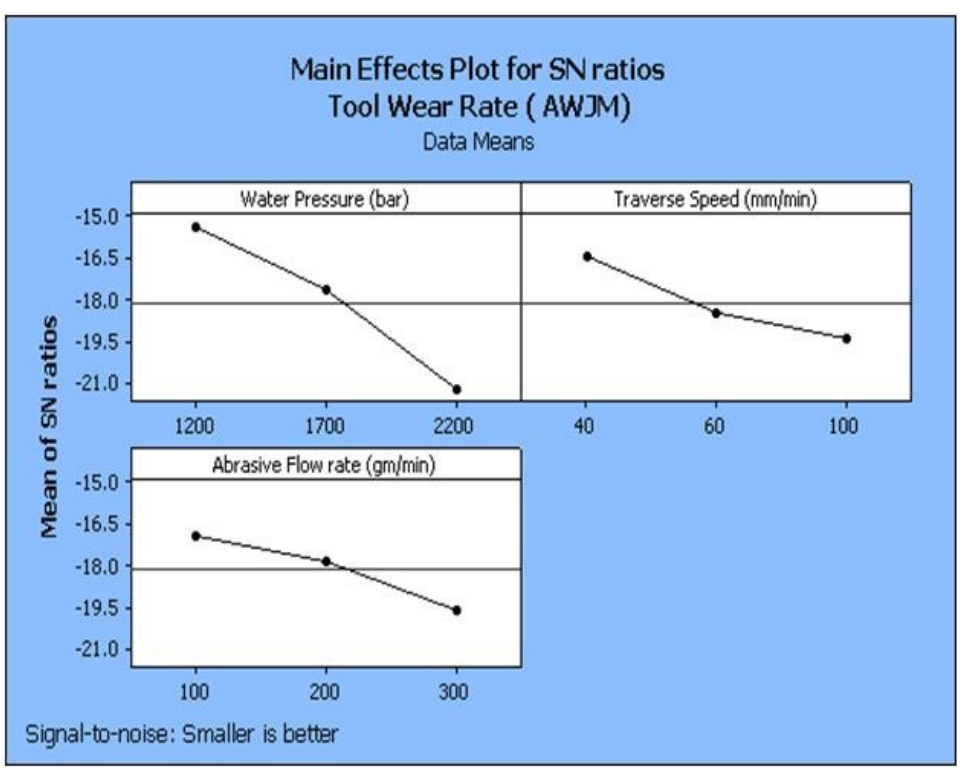

Figure 8. Main effects plot for SN ratios - TWR-AWJM. 
on the MRR as they have p value below 0.05. Similarly all the three factors have $p$ value less that 0.05 they can be considered as influential factors with respect to tool wear rate and surface roughness.

It can be inferred from the Figure 10 that the water pressure $(63.93 \%)$ was the most influential factor followed by traverse speed and abrasive flow rate on material removal rate. Water pressure $(76.25 \%)$ was the most influential parameter on tool wear rate. The traverse speed $(11.93 \%)$ was the second influential parameter followed by abrasive flow rate on tool wear rate. Water pressure $(84.56 \%)$ was the most influential parameter on surface roughness. The traverse speed $(8.76 \%)$ was the second influential parameter followed by abrasive flow rate on surface roughness.

The mathematical model was derived for MRR and given in equation 4.

The regression equation is $=-5.39+0.00866$ Water Pressure (bar) + 0.0694 Traverse Speed $(\mathrm{mm} / \mathrm{min})+$ 0.0244 Abrasive Flow rate (gm/mm) --- Eqn. (4)

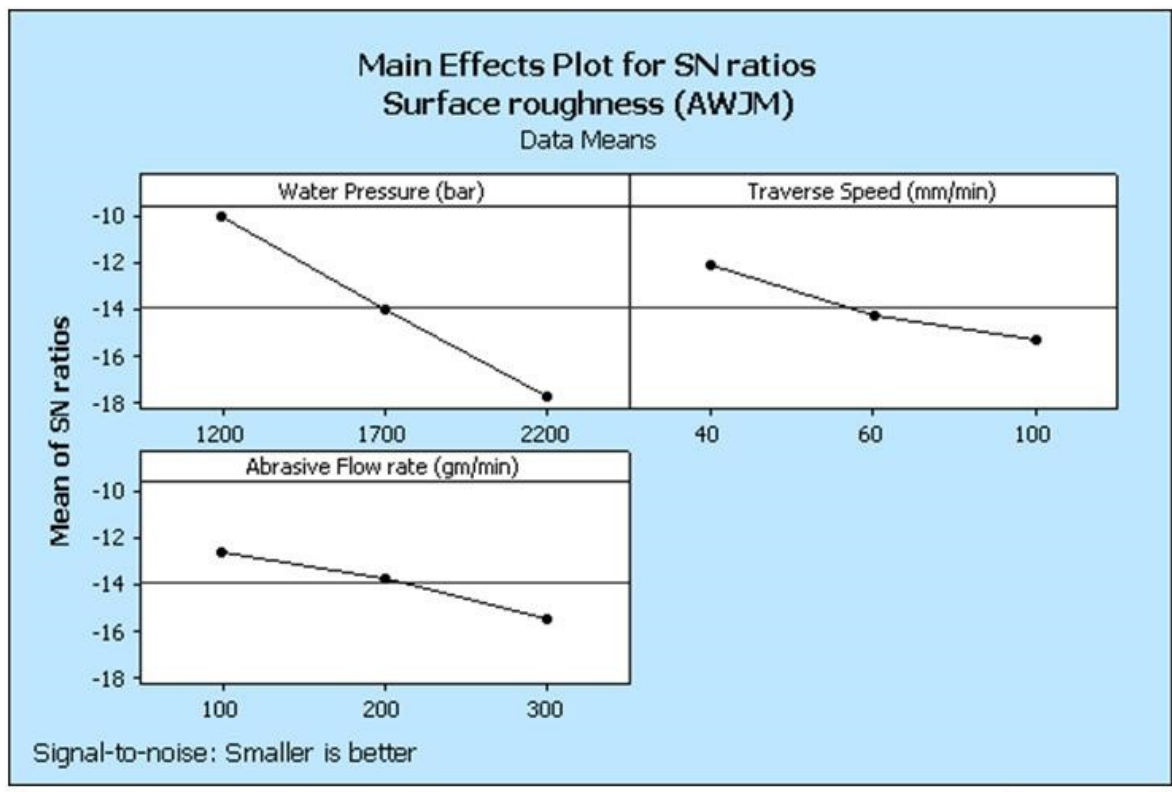

Figure 9. Main effects plot for SN ratios - SR-AWJM.

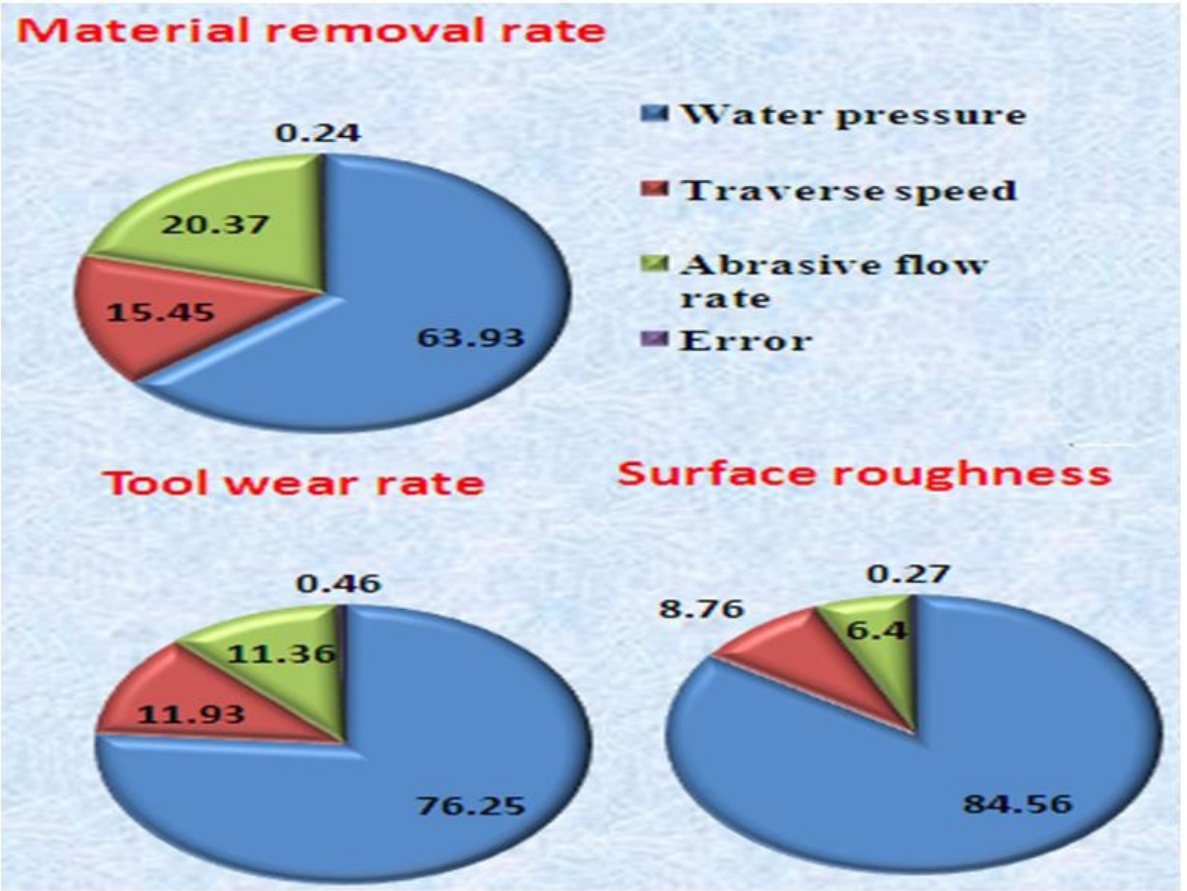

Figure 10. Percentage of contribution for each input parameter on the responses (AWJM). 


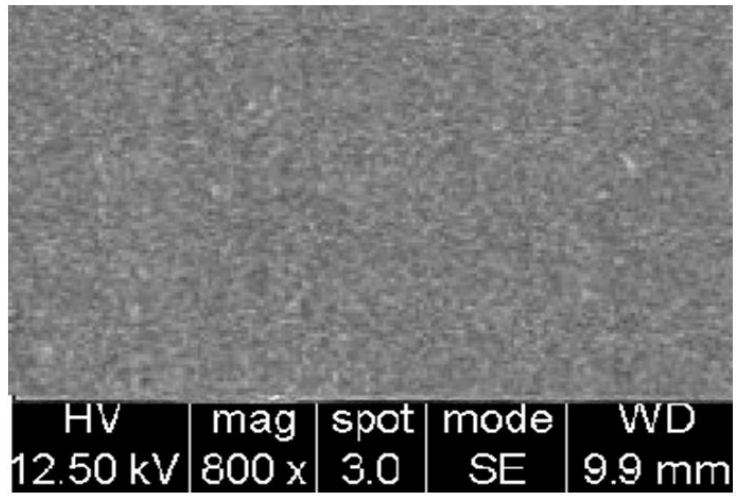

Figure 11. Surface of the material before EDM.

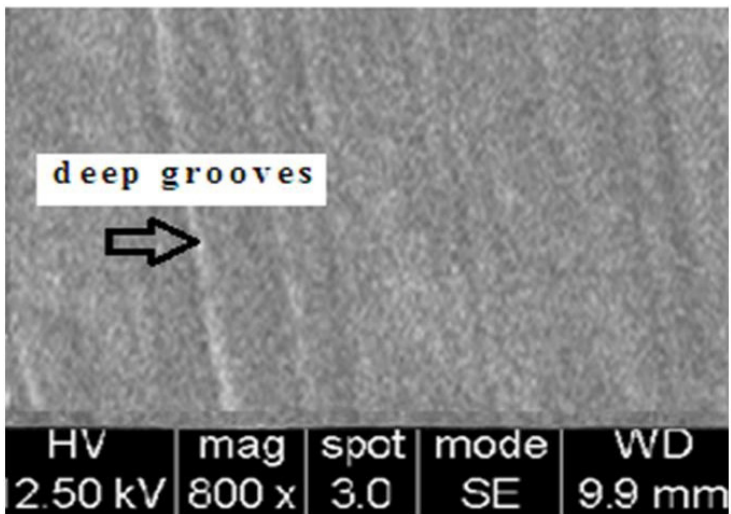

Figure 12. Surface of the material after EDM.

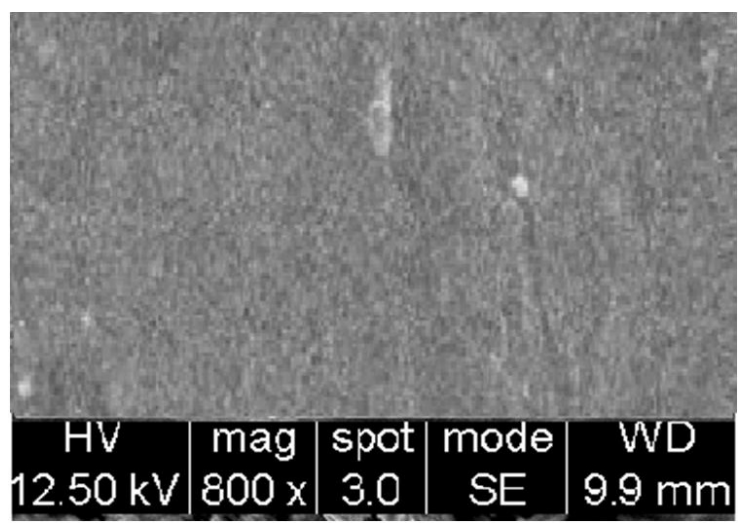

Figure 13. Surface of the material before AWJM.

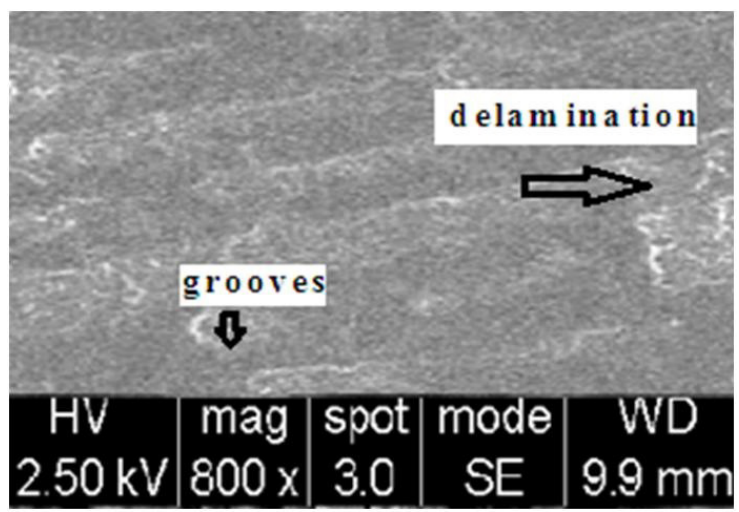

Figure 14. Surface of the material after AWJM.
The mathematical model was derived for TWR and given in equation 5 .

The regression equation is $\mathrm{TWR}=-5.24+0.00546$ Water Pressure (bar) +0.0348 Traverse Speed $(\mathrm{mm} / \mathrm{min})+$ 0.0106 Abrasive Flow rate (gm/mm) -- Eqn. (5)

The mathematical model was derived for SR and given in equation 6 .

The regression equation is $\mathrm{SR}=-4.81+0.00440$ Water Pressure (bar) + 0.0226 Traverse Speed $(\mathrm{mm} / \mathrm{min})+$ 0.00603 Abrasive Flow rate $(\mathrm{gm} / \mathrm{mm})$--- Eqn. (6)

Where $\mathrm{A}, \mathrm{B}$ and $\mathrm{C}$ are water pressure, traverse speed and abrasive flow rate respectively.

\subsection{Surface morphologies}

The machined surface of the composite materials was investigated using SEM images

A scanning electron microscope was employed to investigate the surface quality on the machined surface of the composite. Figure 11 shows the surface of the material before EDM process. Figure 12 shows that surface of the materials after EDM at the optimum level of parameters (current-5A, pulse on time- $100 \mu$ s and voltage-30V). It can be observed from the high magnification SEM image that grooves and scratches appeared on the machined surface.

Figure 13 shows the surface of the composite material before AWJM process. Figure 14 shows that surface of the materials after performing the water jet machining at the optimum level of parameters (water pressure-1200bar, traverse speed $-10 \mathrm{~mm} / \mathrm{min}$ and abrasive flow rate $-100 \mathrm{gm} / \mathrm{min}$ ). It can be seen that the grooves and delamination appeared on the machined surface of the composite specimen.

\section{Conclusion}

The vitallium metal matrix composite was successfully fabricated through stir casting process. This metal matrix was successfully machined through electric discharge machining and abrasive water jet machining processes.

In EDM process maximum MRR was achieved at 15 amps of current, pulse on time of $300 \mu \mathrm{s}$ and voltage of $50 \mathrm{~V}$. Minimum tool wear rate was achieved when the current was 5 amps, pulse on time was $100 \mu$ s and voltage was $50 \mathrm{~V}$. Minimum surface roughness was achieved when the level of current, pulse on time and voltage were $30 \mathrm{~V}, 5 \mathrm{amps}, 100 \mu \mathrm{s}$ and $30 \mathrm{~V}$ respectively. Current and pulse on time were found to be significant factors on the surface roughness.

In AWJM process, maximum MRR was attained when the level of the abrasive flow rate of $100 \mathrm{gm} / \mathrm{mm}$, water pressure of 1200 bar and pulse traverse speed of $40 \mathrm{~mm} / \mathrm{min}$. The minimum surface roughness was achieved at the level of the abrasive flow rate of $100 \mathrm{gm} / \mathrm{mm}$, water pressure of $1200 \mathrm{bar}$ and pulse traverse speed of $40 \mathrm{~mm} / \mathrm{min}$. Water pressure was the most influential parameter on material removal rate, tool wear rate and surface roughness of the composites. The obtained results can be used to get the desired material removal rate and surface finish of the composites. Mathematical equations can be used to predict the MRR, TWR and surface roughness of the material for the new input levels of the parameters. 


\section{References}

1. Çelik H, Kaplan M. Effects of silicon on the wear behavior of cobalt-based alloys at elevated temperature. Wear. 2004;257:606611.

2. Chang S-H, Chen C-C. Microstructure and mechanical properties of cobalt-based alloys strengthened with tantalum carbide powder via vacuum sintering and HIP treatments. Mater Trans. 2014;55(10):1623-9.

3. Suresh SM, Mishra D, Srinivasan A, Arunachalam R, Sasikumar R. Production and characterization of micro and nano $\mathrm{Al} 2 \mathrm{O} 3$ particle-reinforced LM25 Aluminum alloy composites. J Eng Appl Sci (Asian Res Publ Netw). 2011;6(6):94-8.

4. Maneiah D, Shunmugasundaram M, Raji Reddy A, Begum, Z. (2020). Optimization of machining parameters for surface roughness during abrasive water jet machining of aluminium/ magnesium hybrid metal matrix composites. Materials Today: Proceedings. 27(pt 2):1293-98. http://dx.doi.org/10.1016/j. matpr.2020.02.264.

5. Thamizhvalavan P, Arivazhagan S, Yuvaraj N, Ramesh B. Machinability study of abrasive aqua jet parameters on hybrid metal matrix composite. Mater Manuf Process. 2018;34(3):124. http://dx.doi.org/10.1080/10426914.2018.1544707.

6. Yue Z, Huang C, Zhu H, Wang J, Yao P, Liu ZW. Optimization of machining parameters in the abrasive water jet turning of alumina ceramic based on the response surface methodology. Int J Adv Manuf Technol. 2014;71:2107-14.

7. Kechagias J, Petropoulos G, Vaxevanidis N. Application of Taguchi design for quality characterization of abrasive water jet machining of TRIP sheet steels. Int J Adv Manuf Technol. 2012;62:635-43.

8. Pawar PJ, Vidhate US, Khalkar MY. Improving the quality characteristics of abrasive water jet machining of marble material using multi-objective artificial bee colony algorithm. Journal of Computational Design and Engineering. 2018;5(3):319-28. http://dx.doi.org/10.1016/j.jcde.2017.12.002.

9. Ćojbašić Ž, Petković D, Shamshirband S, Tong CW, Ch S, Janković $\mathrm{P}$, et al. Surface roughness prediction by extreme learning machine constructed with abrasive water jet. Precis Eng. 2016;43:86-92. http://dx.doi.org/10.1016/j.precisioneng.2015.06.013.

10. Kumaran ST, Ko TJ, Uthayakumar M, Islam MM. Prediction of surface roughness in abrasive water jet machining of CFRP composites using regression analysis. J Alloys Compd. 2017;724:1037-45. http://dx.doi.org/10.1016/j.jallcom.2017.07.108.

11. Nain SS, Garg D, Kumar S. (2017). Modeling and optimization of process variables of wire-cut electric discharge machining of super alloy Udimet-L605. Engineering Science and Technology, an International Journal, 20(1), 247-264. http:// dx.doi.org/10.1016/j.jestch.2016.09.023.
12. Kar C, Surekha B, Jena H, Choudhury SD. Study of influence of process parameters in electric discharge machining of aluminum - red mud metal matrix composite. Procedia Manufacturing. 2018;20:392-9. http://dx.doi.org/10.1016/j.promfg.2018.02.057.

13. Kanagarajan D, Palanikumar K, Karthikeyan R. Effect of electrical discharge machining on strength and reliability of WC-30\%Co composite. Mater Des. 2012;39:469-74. http:// dx.doi.org/10.1016/j.matdes.2012.03.016.

14. Chakravorty R, Gauri SK, Chakraborty S. Optimization of correlated responses of EDM process. Mater Manuf Process. 2012;27(3):337-47. http://dx.doi.org/10.1080/10426914.2011 .577875 .

15. Mohanty A, Talla G, Gangopadhyay S. Experimental investigation and analysis of EDM characteristics of inconel 825. Mater Manuf Process. 2014;29(5):540-9. http://dx.doi.org/10.1080 /10426914.2014.901536.

16. Singh B, Kumar J, Kumar S. Influences of process parameters on MRR improvement in simple and Powder-Mixed EDM of AA6061/10\% SiC composite. Mater Manuf Process. 2014;30(3):303-12. http://dx.doi.org/10.1080/10426914.201 4.930888 .

17. Sivaraj M, Selvakumar N. Experimental analysis of Al-TiC sintered nanocomposite on EDM process parameters using ANOVA. Mater Manuf Process. 2015;31(6):802-12. http:// dx.doi.org/10.1080/10426914.2015.1048471.

18. Garg RK, Singh KK, Sachdeva A, Sharma VS, Ojha K, Singh $\mathrm{S}$. Review of research work in sinking EDM and WEDM on metal matrix composite materials. Int J Adv Manuf Technol. 2010;50:611-24.

19. Mohd Abbas N, Solomon DG, Fuad Bahari M. A review on current research trends in electrical discharge machining (EDM). Int J Mach Tools Manuf. 2007;47:1214-28.

20. Hung NP, Yang LJ, Leong KW. Electrical discharge machining of cast metal matrix composites. J Mater Process Technol. 1994;44:229-36.

21. Zhang JH, Lee TC, Lau WS. Study on the electro discharge machining of a hot pressed aluminium oxide based ceramic. J Mater Process Technol. 1997;63(4):908-12.

22. Ramulu M, Arola D. The influence of abrasive water jet cutting conditions on the surface quality of graphite/epoxy laminates. Int J Mach Tools Manuf. 1994;34(3)

23. Rajesh R. Effect of chemical treatment on the mechanical properties of palm fiber reinforced polymer composites. Research Journal of Science and Engineering Systems. 2017;1:8-18.

24. Shanmughasundaram $P$. Investigation on the wear behaviour of eutectic Al-Si Alloy- $\mathrm{Al}_{2} \mathrm{O}_{3}$ - Graphite composites fabricated through squeeze casting. Mater Res. 2014;17(4) 